\title{
RELATIONSHIPS BETWEEN TEMPORAL AND SPATIAL VARIATIONS OF WATER QUALITY AND WATER LEVEL CHANGES IN POYANG LAKE BASED ON 5 CONSECUTIVE YEARS' MONITORING
}

\author{
ZHENG, L. ${ }^{1}-$ WANG, H. P. ${ }^{1}-$ HUANG, M. S. ${ }^{2}-$ LIU, Y. ${ }^{1,3 *}$ \\ ${ }^{1}$ College of Water Sciences, Beijing Normal University, 100875 Beijing, China \\ ${ }^{2}$ Beijing Capital Co., Ltd., 100028 Beijing, China \\ ${ }^{3}$ Chinese Research Academy of Environmental Sciences, 100012 Beijing, China \\ *Corresponding author \\ e-mail:liuyan@craes.org.cn \\ (Received 22 ${ }^{\text {nd }}$ Apr 2019; accepted $12^{\text {th }}$ Jul 2019)
}

\begin{abstract}
Quarterly water quality monitoring data from 15 monitoring sites in Poyang Lake and the water level data from the Xingzi monitoring station in Poyang Lake from 2012 to 2016 were analyzed to determine (1) how the water quality changed both spatially and temporally and (2) how the changes of the water quality and eutrophication were related to variations in the water level. The results indicated that there were seasonal and interannual variations in the water quality of Poyang Lake. Dissolved Oxygen (DO) and Total Nitrogen (TN) reached maximum and minimum values in winter and summer, respectively. The maximum and minimum concentrations of Total Phosphorus (TP) were found in spring and summer, respectively. Chemical oxygen demand (COD) was slightly lower in spring and summer than in autumn and winter. Over the entire sampling period, the concentrations of ammonia nitrogen $\left(\mathrm{NH}_{4}-\mathrm{N}\right), \mathrm{TP}$, and $\mathrm{TN}$ were highest in 2015. COD concentrations varied little interannually. Chlorophyll a concentrations were relatively uniform and did not show obvious seasonal variation. There was little spatial variation in the $\mathrm{NH}_{4}-\mathrm{N}$ concentrations in spring and summer, but there was considerable variation between sites in autumn and winter; COD varied considerably between sites in spring and winter. COD and TP were not significantly correlated, but $\mathrm{NH}_{4}-\mathrm{N}, \mathrm{TN}$, and the degree of eutrophication were negatively correlated, with water level changes in Poyang Lake.
\end{abstract}

Keywords: Poyang lake, temporal, spatial, water level changes, TLI, eutrophication

\section{Introduction}

Poyang Lake is the largest freshwater lake in China. Its drainage area, which extends over $16.22 \times 104 \mathrm{~km}^{2}$, accounts for about $9 \%$ of the Yangtze River Basin. It has an average annual runoff of $144 \times 109 \mathrm{~m}^{3}$, which accounts for about $15.5 \%$ of the Yangtze River's average annual runoff (Duan et al., 2016). Poyang Lake makes a significant contribution to the ecological functioning, ecological integrity, and regional management of the water resources of the Yangtze River Basin (Liu et al., 2016). The lake water quality can be recorded by examining the physical, chemical, and biological characteristics of the lake (Van Houtven et al., 2014). It is important to assess the quality of the lake water as it directly affects the safety of the water used by people living close to the lake and the quality of the groundwater. As the largest of all the lakes that are connected to the Yangtze River, its water quality will influence the ecological integrity and ecological functioning in the middle and lower reaches of the Yangtze River. 
Poyang Lake has multiple functions; for example, it provides water for irrigation and domestic needs, is a source of aquatic products, and is an important shipping route (Wu et al., 2017). In recent years, the water quality has been affected by industrial discharges, agricultural effluent, and domestic sewage, to the point and that the ecological function of the wetland has been compromised, with consequences for the water supply capacity of the lake. More pollutants from upstream and the lower water levels in the dry season together indicate that eutrophication will increase in Poyang Lake. In recent years, many researchers have studied spatial and temporal changes in the water environment and the trophic status in Poyang Lake. For example, Hu et al. (2010) using the Nimero index, found that the conditions in Poyang Lake were eutrophic because of excessive nitrogen and phosphorus in 2010. Wu et al. (2011) found that water quality of Poyang Lake has already undergone great changes after 2003, and it is showing a deterioration trend, while Gao et al. (2010) found that in 2010, the main pollutants affecting the water quality of the lake were TP and TN. The water level in Poyang Lake is affected by climatic conditions and human activities and, because it is directly connected to the Yangtze River, the seasonal fluctuations in the water level are quite pronounced. Therefore, the relationship between water level changes and eutrophication has definite implications for water resources management (Coops et al., 2003). In their study, Wu et al. (2014) used water quality indicators to examine the temporal and spatial changes in the water quality of Poyang Lake in 2017 and also examined how these changes were related to the water level. Wang et al. (2015) used SWAT and GIS to quantitatively estimate how the exchanges between the river and lake influenced the dissolved nutrient loads in Poyang Lake and also the spatial and temporal changes in the wetland vegetation in 2015. Liu et al. (2013) collected samples of surface water from the main part of Poyang Lake, the entrance of five rivers to Poyang Lake, and the dish-shaped sub-lake, and it was found that there was serious eutrophication in 2013. Ma et al. (2013) analyzed the changes in the water quality in Poyang Lake from 2008 to 2010 and used the load analysis method to determine the main sources of the pollution in the lake in 2013. Du et al. (2015) quantitatively analyzed the relationships between the water quality of Poyang Lake and the water levels during the wet and dry seasons in 2015. They found that the water supply was increasingly inadequate to meet the demands of the gradually more intensive industries and livestock and poultry breeding activities in the Poyang Lake area, that the surrounding environment had been destroyed, and the water quality in the lake had deteriorated rapidly. The spatial and temporal variations in the water quality of Poyang Lake and the trophic status of the lake have been intensively studied. However, few studies have focused on the relationship between water quality and the water levels in Poyang Lake, and very few studies have systematically analyzed how water levels influence the water environment.

In this study, five years continuum water quality monitoring data of Poyang Lake were analyzed and the trophic status was evaluated to find out how the water quality in the lake varied both spatially and temporally over recent years. The effects of water level changes on the spatial and temporal changes in the water quality and eutrophication in different seasons and at a range of spatial scales were also examined. The results of this study will provide useful information about how the water quality in Poyang Lake varies both spatially and temporally and how the water quality is related to the water level. This study will also provide support for making scientifically robust decisions about how to implement tools to control the pollution in the lake, restore the aquatic ecosystems, allocate and protect water resources in an effective way. 


\section{Materials and methods}

\section{Study area}

Poyang Lake is in the northern part of Jiangxi Province, at the southern end of the middle to lower reaches of the Yangtze River. Poyang Lake has five main inflows (including the Raohe River, Ganjiang River, Fuhe River, Xinjiang River, and the Xiushui River) and drains into the Yangtze River from its northern end. Most of the lake's water area (97\%) (Lai et al., 2014) is in Jiangxi Province. With Songmen Mountain as its boundary, the main body of the lake is to the south, while the channel that connects with the Yangtze River is at the northern end. Poyang Lake is $173 \mathrm{~km}$ long from north to south. It is between 3 and $74 \mathrm{~km}$ wide from east to west with an average width of $16.90 \mathrm{~km}$. The lake basin slopes from the southeast to the northwest and the shoreline is approximately $1200 \mathrm{~km}$ long (Yao et al., 2018). The average water level in Poyang Lake is between 14 and $15 \mathrm{~m}$ (Liu et al., 2016) and there are considerable seasonal and interannual variations in the water level. Records show maximum annual variations between 9.59 and $15.36 \mathrm{~m}$, and minimum annual variations between 3.80 and $9.79 \mathrm{~m}$ (Dai et al., 2016). The water level changes seasonally in Poyang Lake. During the dry season, the water level drops, and the beach is exposed; it then rises during the wet season and the landscape is very different from that in the dry season (Yuan et al., 2015). The water level in the lake is generally highest between June and August, and lowest between December to February (Lan, 2014).

\section{Data sources}

In this study, 15 monitoring stations were specifically chosen to account for the lake's unique hydrological conditions, shape, and different functional areas were set up in Poyang Lake, as shown in Figure 1. Samples were collected in January, April, July, and October of each year from January 2012 to December 2016. Data for the water level were obtained from the Jiangxi Provincial Hydrographic Bureau. Water level from January, April, July, and October at the Xingzi Monitoring Station from 2012 to 2016 were used to represent the average condition in Poyang Lake. The spatial distribution pattern of water quality is demonstrated using the data of 2012.

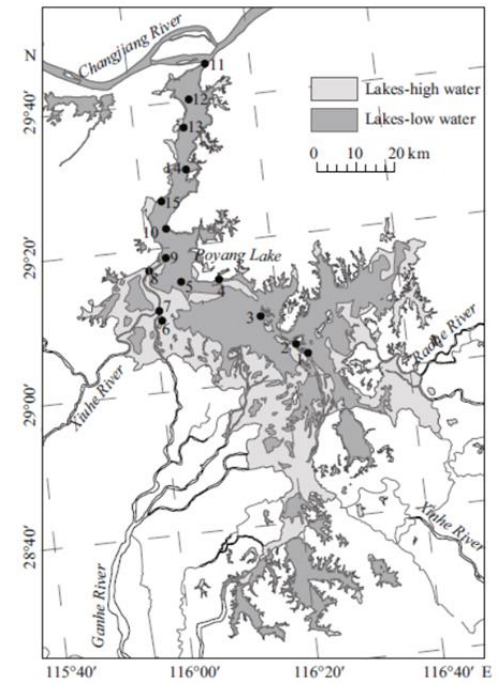

Figure 1. Location and sampling point distribution of Poyang Lake 


\section{Water sample analysis}

Lake surveys were conducted following the procedures outlined in The Lake Ecosystem Observation Method. The transparency was determined with a Secchi Disc (SD), chemical oxygen demand $\left(\mathrm{COD}_{\mathrm{MN}}\right)$ was determined by acid potassium permanganate titration, TN concentrations were determined by ultraviolet spectrophotometry after digestion with alkaline potassium persulfate, TP concentrations were determined by ammonium molybdate spectrophotometry, and chlorophyll a (Chla) was determined after hot ethanol extraction.

\section{Lake eutrophication evaluation method}

The nutrient status of the lake was determined with the trophic level index (TLI), based on Chla, TP, TN, SD, and COD MN (El-Serehy et al., 2018; NapiórkowskaKrzebietke et al., 2013; Trolle et al., 2014).

The numerical values of the trophic level index (TLI) for the Poyang Lake water were calculated using the following equation:

$$
T L I(\Sigma)=\sum_{j=1}^{m} W_{j} \cdot T L I(j)
$$

In which TLI = trophic level index; $W_{j}=$ weight of the TLI parameter; $\mathrm{m}=$ Number of parameters participating in the evaluation.

$$
W_{j}=r_{i j}^{2}\left(\sum_{j=1}^{m} r_{i j}^{2}\right)^{-1}
$$

In which $r_{i j}=$ Correlation coefficient between each parameter and Chla parameter. The values are shown in Table 1.

Table 1. A certain lake's parameter correlated $\boldsymbol{r}_{\tilde{i f}}$ and $\boldsymbol{r}_{i \mathrm{if}}{ }^{2}$ of Chla*

\begin{tabular}{c|c|c|c|c|c}
\hline Parameter & Chla & TP & TN & SD & COD MN \\
\hline$r_{i j}$ & 1 & 0.84 & 0.82 & -0.83 & 0.83 \\
$r_{i j}{ }^{2}$ & 1 & 0.7056 & 0.6724 & 0.6889 & 0.6889 \\
\hline
\end{tabular}

*From the calculation results of 26 major Chinese lake survey data

$$
\begin{gathered}
T L I(C h l)=10(2.5+1.086 \ln C h l) \\
T L I(T P)=10(9.436+1.624 \ln T P) \\
T L I(T N)=10(5.453+1.694 \ln T N) \\
T L I(S D)=10(5.118-1.94 \ln S D) \\
T L I\left(C O D_{M N}\right)=10\left(0.109+2.661 \ln C O D_{M N}\right)
\end{gathered}
$$

When the TLI was less than 30, the lake was oligotrophic; TLI values of between 30 and 50 indicated oligotrophic/mesotrophic conditions; TLI values of between 50 and 60 


$$
-11691 \text { - }
$$

indicated mild eutrophication; values between 60 and 70 indicate moderate eutrophication, while values greater than 70 indicate severe eutrophication.

\section{Result and discussion}

\section{Temporal variations in the water quality in Poyang Lake}

Information about seasonal variations in the various water quality indicators in Poyang Lake from 2012 to 2016 is presented in Figure 2. The concentrations and data for the four quarters indicate seasonal differences. The patterns in the concentrations of DO and TN were the same. DO and TN concentrations were lowest in summer (July) and highest in winter (January). The DO concentrations were 6.59 and $12.72 \mathrm{mg} / \mathrm{L}$, while the TN concentrations were 1.50 and $2.40 \mathrm{mg} / \mathrm{L}$ in summer (July) and winter (January), respectively. The concentrations in spring (April) and autumn (October) showed little variation and fell between the maximum winter values and minimum summer values. The $\mathrm{NH}_{4}-\mathrm{N}$ concentrations varied widely over the year and ranged from 0.16 to $0.51 \mathrm{mg} / \mathrm{L}$. They were low in spring and summer and high in autumn and winter.
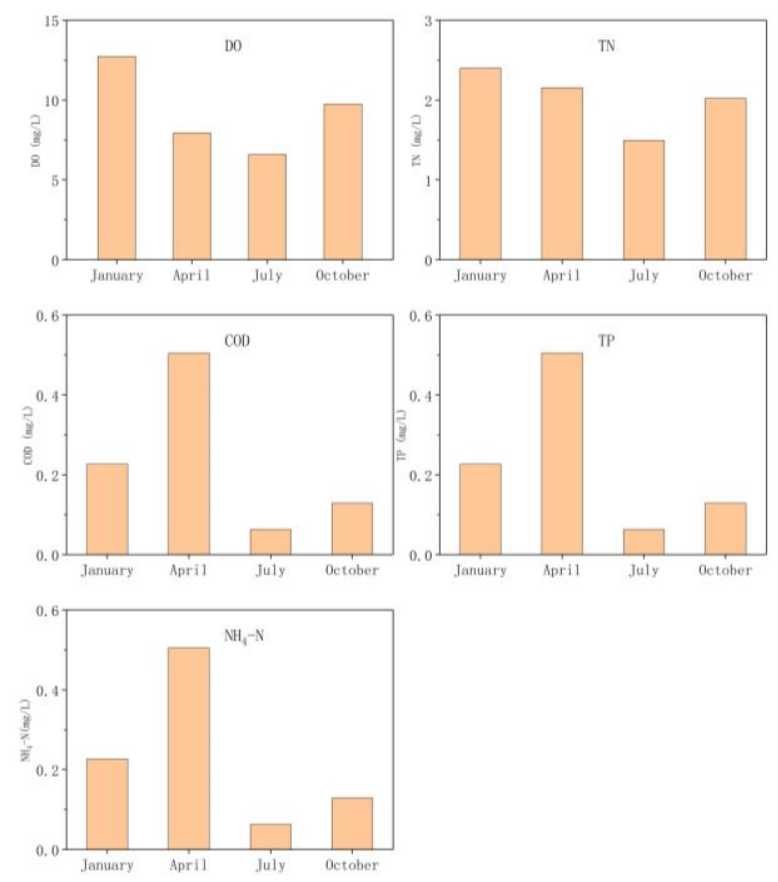

Figure 2. Summary information about seasonal variations in the water quality indicators during the year

There was considerable interannual variation in the various water quality indicators in Poyang Lake from 2012 to 2016, as shown in Figure 3. The concentrations of $\mathrm{NH}_{4}$ $\mathrm{N}, \mathrm{TP}$, and TN reached maximum values of $0.56,1.30$, and $4.25 \mathrm{mg} / \mathrm{L}$, respectively, in 2015 and these concentrations were considerably higher than those in the other years. The concentrations of these indicators were similar in the other years. The concentrations of $\mathrm{NH}_{4}-\mathrm{N}$ and TN were about $50 \%$ higher in 2015 than those in the other years, while, compared to 2015, the concentrations of TP were much lower in the other 


$$
-11692 \text { - }
$$

years and were generally below $0.3 \mathrm{mg} / \mathrm{L}$. Concentrations of COD ranged from 2.24 to $3.15 \mathrm{mg} / \mathrm{L}$ and showed little between-year variation.
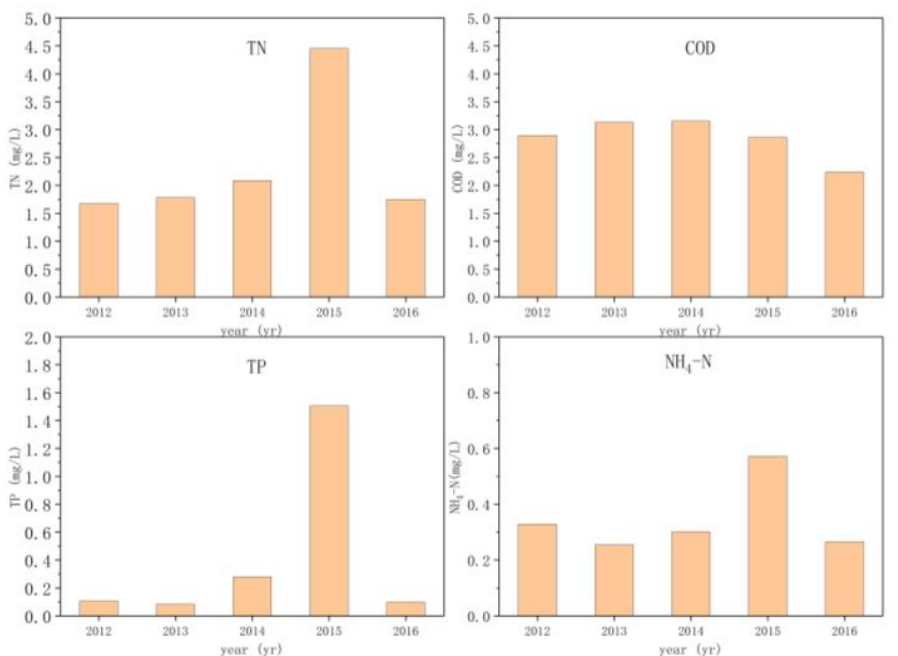

Figure 3. Inter-annual variation in the water quality indicators

\section{Spatial variations in the water quality in Poyang Lake}

The TN concentrations in Poyang Lake were high in autumn and winter and low in summer and autumn (Fig. 4). In winter (January), the TN concentration exceeded $2.0 \mathrm{mg} / \mathrm{L}$ across all of Poyang Lake, and did not differ significantly between the sampling sites. The TN concentration ranged from a minimum of about $1.8 \mathrm{mg} / \mathrm{L}$ in the western part of the lake and reached a maximum of about $3.0 \mathrm{mg} / \mathrm{L}$ in the southeastern part of the lake. In spring (April), the average TN concentration in the whole lake was relatively low and, at about $1.5 \mathrm{mg} / \mathrm{L}$, did not differ significantly across the whole lake. In the northern part of the lake, the $\mathrm{TN}$ concentration reached a maximum of about $1.9 \mathrm{mg} / \mathrm{L}$. The TN concentrations in summer and spring across the whole lake were similar. The average concentration in summer was about $1.5 \mathrm{mg} / \mathrm{L}$ and did not differ much across the whole lake, with high concentrations of up to $2.0 \mathrm{mg} / \mathrm{L}$ in only a few northern and central areas. In autumn (October), the TN concentrations were high in the south and low in the north. They were relatively low in the northern part (about $1.5 \mathrm{mg} / \mathrm{L}$ ) in the channel that connected the lake to the river, and were relatively high (up to $2.0 \mathrm{mg} / \mathrm{L}$ ) in the southern part of the lake.

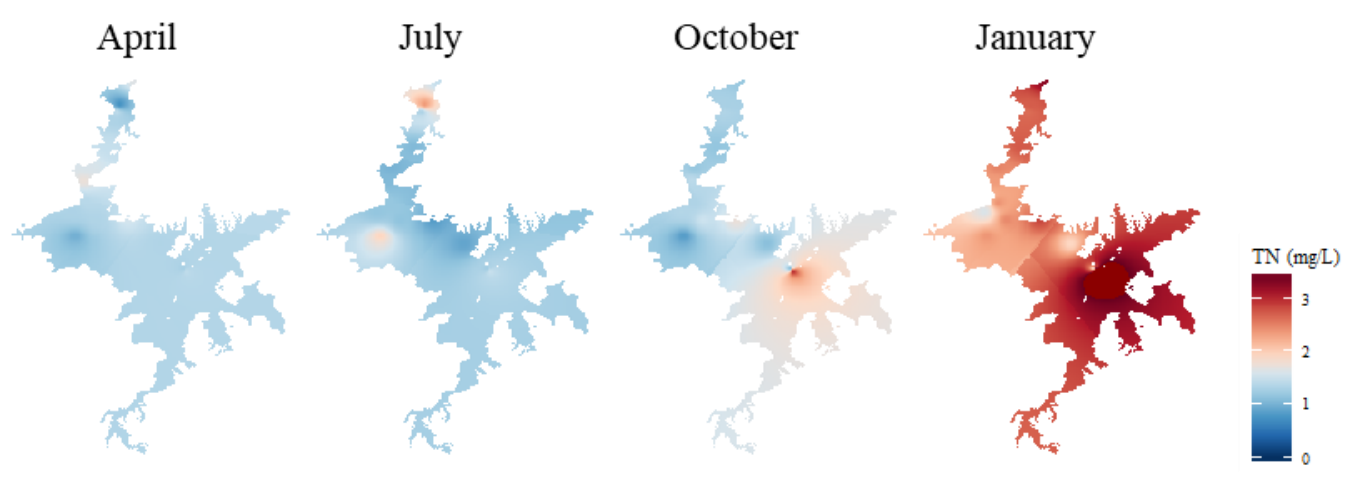

Figure 4. Temporal and spatial distribution of TN in Poyang Lake 
Similar to TN, the TP concentrations were high in autumn and winter and low in spring and summer (Fig. 5). In winter (January), the TP concentrations were higher in the southern part and lower in the northern part. The TP concentration reached $0.2 \mathrm{mg} / \mathrm{L}$ in the southern lake area, and was only $0.1 \mathrm{mg} / \mathrm{L}$ in the channel that connects the lake with the river in the north. In spring (April), the TP concentration showed little variation and was low across the whole lake $(0.08 \mathrm{mg} / \mathrm{L})$. The patterns in spring and summer (July) were similar. In summer, the concentrations were low (about $0.1 \mathrm{mg} / \mathrm{L}$ ) and were relatively uniform across most of the lake, but were slightly higher $(0.15 \mathrm{mg} / \mathrm{L})$ in some areas, such as in the channel that connects the lake to the river in the north. The TP concentrations were highest in autumn (October) across the whole lake. The distribution of the TP concentrations in autumn and winter were similar, and were high in the south and low in the north. The TP concentrations in the lake were much higher in autumn than in winter, and exceeded $0.2 \mathrm{mg} / \mathrm{L}$ in most of the southern part of the lake, with concentrations greater than $0.3 \mathrm{mg} / \mathrm{L}$ in some places.
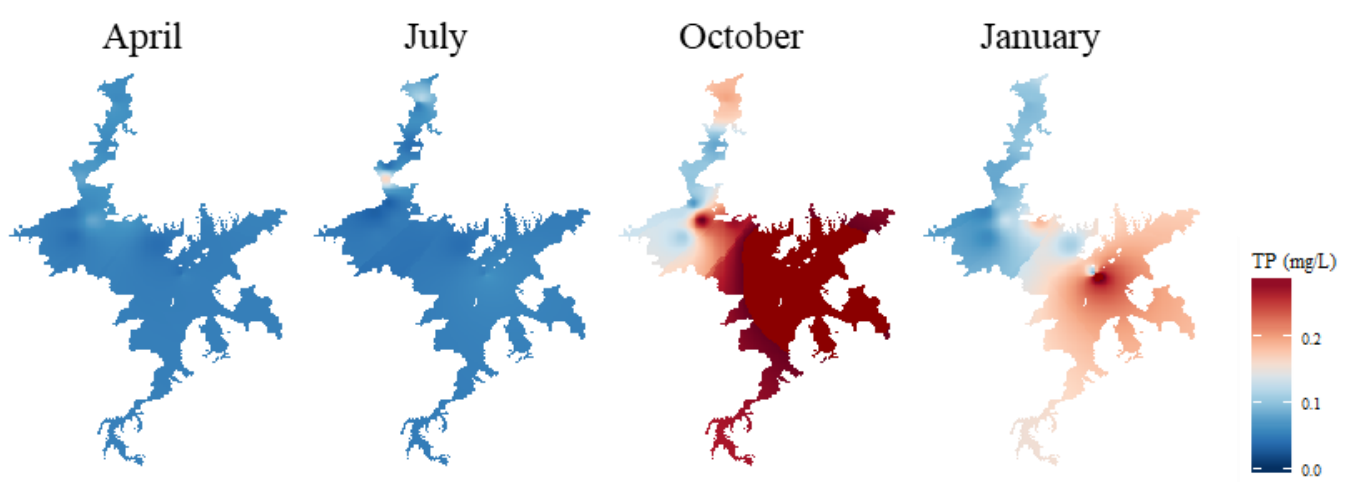

Figure 5. Temporal and spatial distribution of TP in Poyang Lake

Chlorophyll a was uniformly distributed in the lake both spatially and temporally (Fig. 6). The concentrations of Chla in the lake were lower in winter than in the other seasons, and were lower than $3.0 \mathrm{mg} / \mathrm{L}$ across the whole lake during the season. The concentrations of Chla were highest in the northwestern part of the lake. In summer (July), the Chla concentration reached a maximum value of about $15.0 \mathrm{mg} / \mathrm{L}$ at a monitoring station near Wucheng Town. The high values may attribute to the higher water consumption during summer in tourist towns, which results in higher pollutant loads, worse water quality, and causes algae to proliferate in the lake.
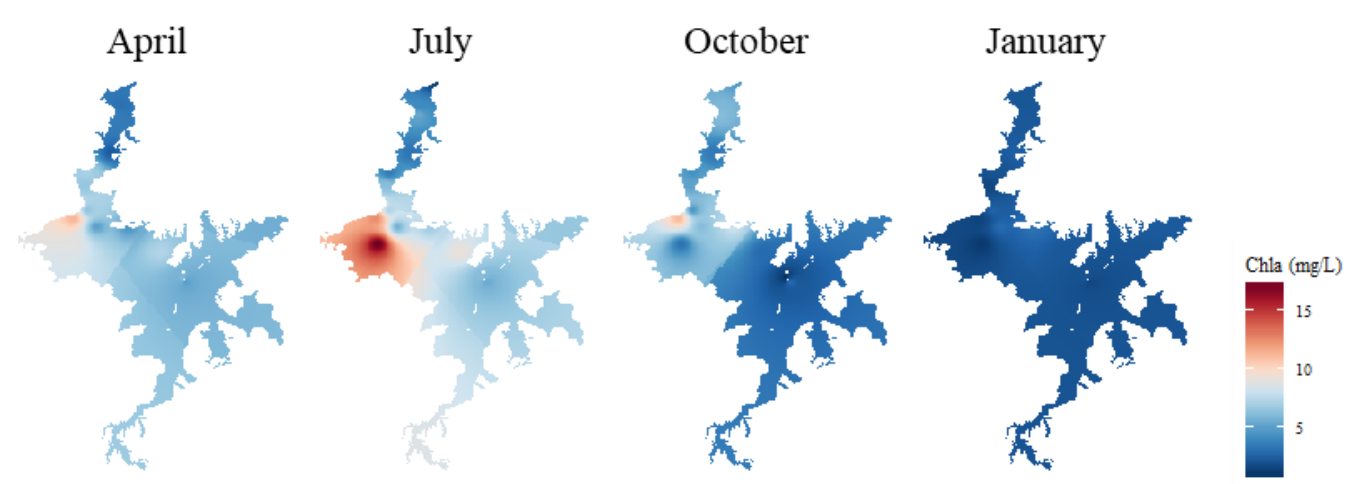

Figure 6. Temporal and spatial distribution of Chla in Poyang Lake 
The $\mathrm{NH}_{4}-\mathrm{N}$ concentrations in Poyang Lake demonstrated little variation in spring and summer, and large variations in autumn and winter (Fig. 7). In spring, the $\mathrm{NH}_{4}-\mathrm{N}$ concentrations were generally low, with an average of about $0.2 \mathrm{mg} / \mathrm{L}$, and were relatively uniform across the lake. The spring and summer situations were similar. In summer, the $\mathrm{NH}_{4}-\mathrm{N}$ concentrations were relatively uniform across the whole lake and averaged about $0.1 \mathrm{mg} / \mathrm{L}$. In the autumn, the $\mathrm{NH}_{4}-\mathrm{N}$ concentrations varied considerably across the lake and were high in the south and low in the north. The $\mathrm{NH}_{4}-\mathrm{N}$ concentration was about $0.5 \mathrm{mg} / \mathrm{L}$ in the channel that connects the northern part to the river, and was about $1.2 \mathrm{mg} / \mathrm{L}$ in the southern part of the lake. By contrast in autumn, the concentrations were high in the north and low in the south in the winter. The concentrations reached a maximum of about $1.0 \mathrm{mg} / \mathrm{L}$ in the northern part of the lake, but were only about $0.5 \mathrm{mg} / \mathrm{L}$ in most of the southern part of the lake.
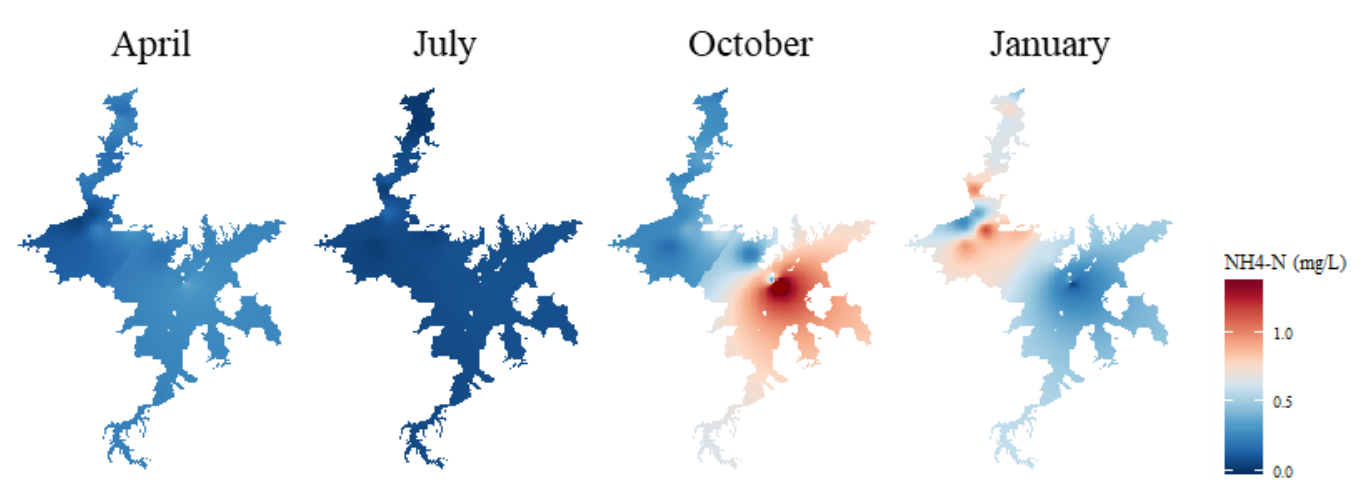

Figure 7. Temporal and spatial distribution of $\mathrm{NH}_{4}-\mathrm{N}$ in Poyang Lake

The $\mathrm{COD}_{\mathrm{MN}}$ in Poyang Lake showed considerable variation in spring and winter but varied little across the lake in summer and autumn (Fig. 8). In spring, the $\mathrm{COD}_{\mathrm{MN}}$ was high in the north and low in the south. The COD MN $_{\text {was }}$ high, up to $4.0 \mathrm{mg} / \mathrm{L}$, in the channel that connects with the river channel in the north, but was about $3.5 \mathrm{mg} / \mathrm{L}$ in most of the southern lake. The COD $_{M N}$ did not vary much throughout the lake in summer and autumn, and remained about $2.0 \mathrm{mg} / \mathrm{L}$. Similar to the spring distributions, the concentrations were high in the north and low in the south in winter. The COD $\mathrm{MN}$ reached $5.0 \mathrm{mg} / \mathrm{L}$ in the north where the lake was connected with the river channel, but was mainly between 3.0 and $3.5 \mathrm{mg} / \mathrm{L}$ in the southern part.
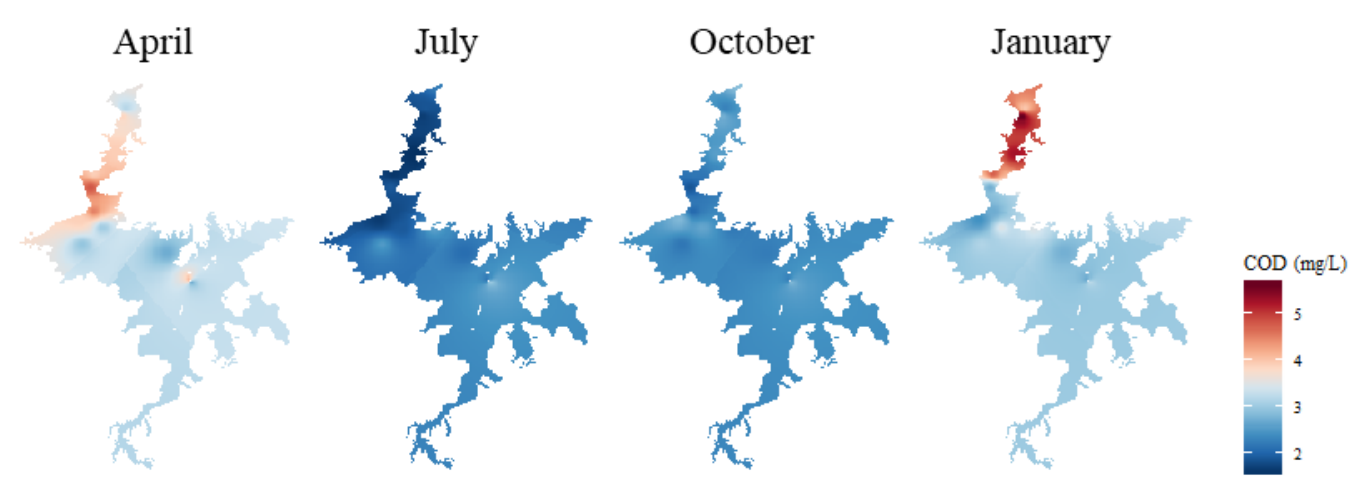

Figure 8. Temporal and spatial distribution of $C O D_{M N}$ in Poyang Lake 


\section{The influence of changes in the water level on the water quality of Poyang Lake}

The correlations between the concentrations of $\mathrm{COD}_{\mathrm{MN}}, \mathrm{NH}_{4}-\mathrm{N}, \mathrm{TN}$, and TP concentrations and the water level in Poyang Lake at the Xingzi Hydrological Station are shown in Figure 9. There were no significant correlations between COD $_{\mathrm{MN}}$ and TP and the changes in the water level. The concentrations of $\mathrm{NH}_{4}-\mathrm{N}$ and $\mathrm{TN}$ were strongly and negatively correlated with the changes in the water level, with correlation coefficients of 0.31 and 0.19 , respectively $(\mathrm{p}<0.05)$; the concentrations of $\mathrm{NH}_{4}-\mathrm{N}$ and $\mathrm{TN}$ in the lake were affected by the water level, and the concentrations gradually decreased as the water level increased.
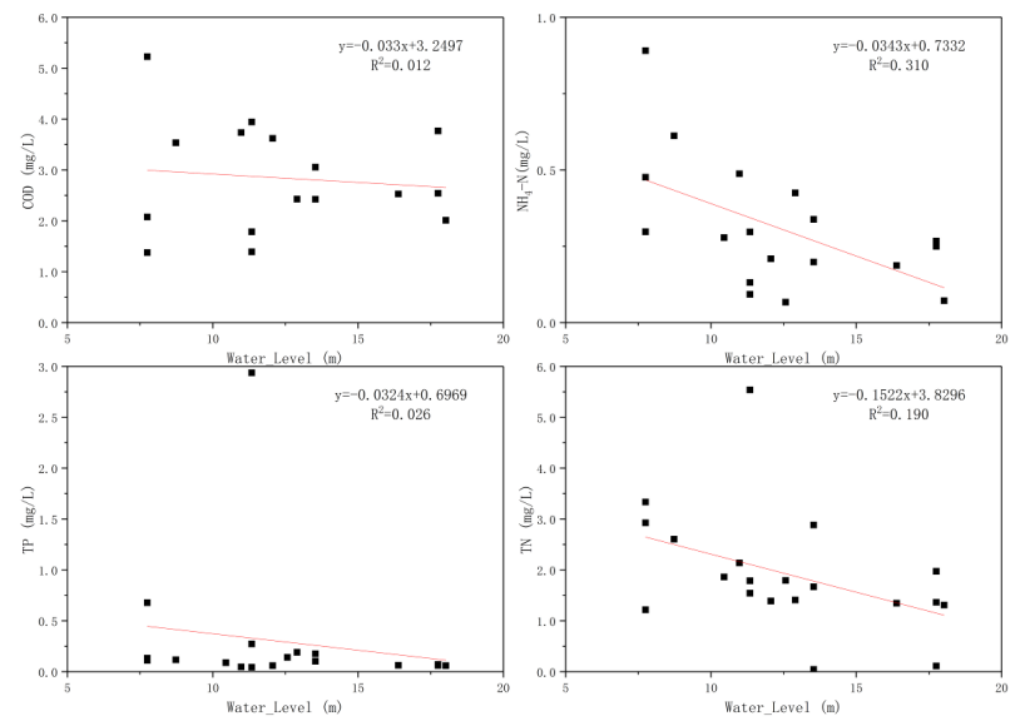

Figure 9. Correlations between the water quality indicators and the water level

\section{The influence of changes in the water level in Poyang Lake on the degree of eutrophication}

The average TLI in Poyang Lake was 48.35, which indicates mesotrophic conditions. There was little variation in the overall trophic status of the lake (Fig. 10). At Site 1, on the central/eastern part of the lake, the TLI reached a maximum of 50.20. At Site 7, on the northwestern/central part of the lake, the nutrient TLI was lowest at 45.65. The conditions at Site 1 and Site 5, which accounted for $13 \%$ of the sites, were mildly eutrophic, while the conditions at the remaining sites, or $87 \%$, were mesotrophic. Poyang Lake is generally mesotrophic, and the trophic status does not show much spatial variation.

The TLI was negatively correlated with the water level $\left(R^{2}=-0.62\right)$, so that as the water level increased, the TLI, and also the degree of eutrophication, decreased accordingly. The TLI (Chla) and the water level $\left(\mathrm{R}^{2}=0.24\right)$ were weakly and positively correlated, but the TLI (TP), TLI (SD), and TLI (COD $\left.{ }_{M N}\right)$ were negatively correlated with the water level $\left(\mathrm{R}^{2}=-0.52, \mathrm{R}^{2}=-0.41\right.$, and $\left.\mathrm{R}^{2}=-0.35\right)$. As shown in Figure 11, there was a strong negative correlation between the TLI (TN) and the water level $\left(\mathrm{R}^{2}=-0.75\right)$, so that, as the water level increased, the TLI decreased.

As the water level increased, the TLI decreased in areas affected by TN, TP, transparency, and COD ${ }_{M N}$. Conversely, as the water level decreased, the TLI increased in areas affected by TN, TP, transparency, and $\mathrm{COD}_{\mathrm{MN}}$. In general, the TLI was negatively 
correlated with the water level of Poyang Lake. The TLI was also negatively correlated with the water level. As the water level increased, the TLI decreased and vice verse.

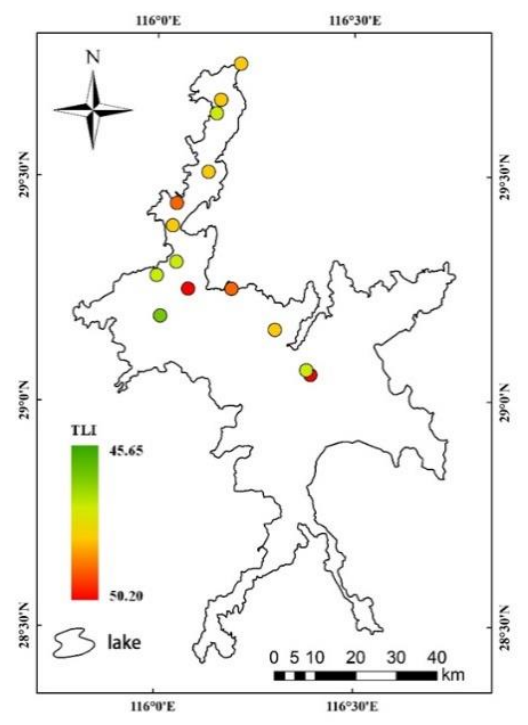

Figure 10. Spatial distribution of the TLI in Poyang Lake

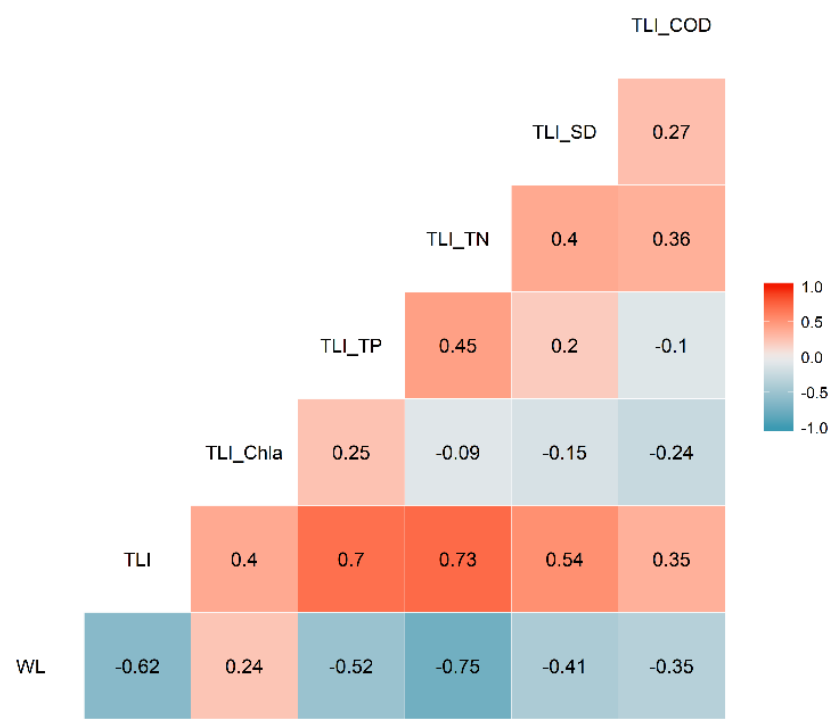

Figure 11. The relationships between the TLI and various water quality indicators and water level (WL) in Poyang Lake

\section{Factors influencing temporal and spatial variations in the water quality in Poyang} Lake

The water level regulates the structure and function of natural lake ecosystems. The water levels in lakes connecting with the Yangtze River change quite considerably over the course of a year. The large fluctuations in the water level of Poyang Lake will therefore affect the hydraulic retention time, the time taken for water to exchange, and the growth and energy exchange of phytoplankton. We found that, on an annual time 
scale, the water level in Poyang Lake was highest in summer, the TLI was negatively correlated with the water level, and the fluctuation in the water level had the most important influence on TN. In the study of Poyang Lake from 2009 to 2014, Wu et al. (2017) found that the nutrients in the lake would be diluted in 2017 because of seasonal increases in the water level, thereby reducing the eutrophication in the lake. In the study of Poyang Lake from 2008 to 2012, Liu et al. (2014) confirmed that the trophic level was lower at higher water levels than at lower water levels in 2014. However, as the lake level and water volume decrease, sediment will be resuspended and nutrients will be released. The water level in Poyang Lake is higher in summer than in winter, so more sediment will be resuspended in winter than in summer, resulting in more serious eutrophication in winter than in summer. As shown in numerous previous studies, higher water levels will decrease eutrophication by Mao et al. (2014). In addition, Poyang Lake is connected to the Yangtze River. When the water level is high in summer, water is exchanged rapidly between them, so the degree of eutrophication is low. In winter, the water level is lower and it takes longer for the water to exchange, so the degree of eutrophication is higher. The change in the degree of eutrophication in the lake area following temporal changes in the water level can be explained by dilution of nutrients as the water level rises during precipitation, resuspension of sediments and release of nutrients when the water levels are low, and the time taken for water to turn over. The changes in the water level were correlated with the TLI for TN, TP, transparency, and $\mathrm{COD}_{\mathrm{MN}}$, and the factors that influenced the changes are consistent with those that influenced the TLI. The content of Chla is not related to changes in the water level, mainly because Chla is influenced by the water temperature, algal biomass, light, and suspended matter. The water level can, however, affect the light and the concentrations of suspended matter what is limited for shallow lakes.

The changes in the water level have little effect on how the trophic state varies spatially, and previous studies have not shown that the water level was related to the spatial distribution of the trophic state by Wang et al. (2013). The results of this study show that spatial variations in the trophic state of Poyang Lake are mainly affected by the pollutants transported into the lake from urban and industrial areas. There is no clear relationship between the water level of Poyang Lake and its trophic status. Some of the sampling points were in the main channel that connected the lake with the river. At these points, the water exchange is faster than in the main body of the lake and the selfpurification ability is strong, so the pollutants gradually dilute and degrade; the degree of eutrophication is low and is only weakly related to the water level. Other monitoring points are polluted by agricultural, industrial, and domestic activities.

\section{Conclusions}

The water quality of Poyang Lake showed seasonal changes at the annual scale. The concentrations of DO and TN were lowest in summer and highest in winter, with little difference in spring and autumn. The concentrations of TP reached maximum and minimum values in spring and summer, respectively. COD was slightly lower in spring and summer than in autumn and winter. Concentrations of $\mathrm{NH}_{4}-\mathrm{N}$ were low in spring and summer, and high in autumn and winter. The water quality of Poyang Lake also varied inter annually. Concentrations of $\mathrm{NH}_{4}-\mathrm{N}$, TP, and TN reached maximum values of $0.56,1.30$, and $4.25 \mathrm{mg} / \mathrm{L}$, respectively, in 2015 , but did not vary much in the other years. Concentrations of $\mathrm{NH}_{4}-\mathrm{N}$ and $\mathrm{TN}$ were about 50\% higher in 2015 than in other 
years; TP concentrations were much higher in 2015 than in the other years, when they remained below $0.3 \mathrm{mg} / \mathrm{L}$. The COD concentrations did not vary much between years.

There were seasonal spatial variations in the water quality in Poyang Lake. The TN concentrations across the whole lake in winter generally exceeded $2.0 \mathrm{mg} / \mathrm{L}$, while in the spring and summer, the TN concentrations were about $1.5 \mathrm{mg} / \mathrm{L}$. In the autumn, the TN concentrations were high in the south and low in the north. In winter, the TP concentrations were high in the south and low in the north. The concentrations of TP were low across the entire lake in the spring and summer. In autumn, the TP concentrations were much higher than in the winter, and were high in the south and low in the north. The $\mathrm{NH}_{4}-\mathrm{N}$ concentrations in Poyang Lake were generally low at $0.2 \mathrm{mg} / \mathrm{L}$, and showed little spatial variation across the whole lake. The $\mathrm{NH}_{4}-\mathrm{N}$ concentrations across the whole lake were low in summer. In the autumn and winter, the $\mathrm{NH}_{4}-\mathrm{N}$ concentrations in the lake were high in the south and low in the north, and high in the north and low in the south, respectively. In the autumn, $\mathrm{NH}_{4}-\mathrm{N}$ concentrations were high in the south and low in the north, while the pattern was the opposite in winter. $\mathrm{COD}_{\mathrm{MN}}$ in the lake in spring and winter was high in the north and low in the south. CODMN did not vary significantly on the spatial scale in summer and autumn and was generally low.

Poyang Lake was mesotrophic, and the trophic status was relatively uniform. The TLI of Poyang Lake were negatively correlated with the water level. Of the water quality indicators, TN was most affected by the changes in the water level of Poyang Lake. On the temporal scale, the TLI of Poyang Lake was negatively correlated with the water level. The trophic status of Poyang Lake was spatially heterogeneous and was not affected much by the water level.

Acknowledgements. We are grateful to all staff that collected and processed samples for the monitoring program from the Poyang Lake Laboratory for Wetland Ecosystem Research (PLWER).

\section{REFERENCES}

[1] Coops, H., Beklioglu, M., Crisman, T. L. (2003): The role of water-level fluctuations in shallow lake ecosystems - workshop conclusions. - Hydrobiologia 506-509(1-3): 23-27.

[2] Dai, X., Wan, R., Yang, G., et al. (2016): Responses of wetland vegetation in Poyang Lake, China to water-level fluctuations. - Hydrobiologia 773(1): 1-13.

[3] Du, Y., Zhou, H., Peng, W., et al. (2015): Hydrodynamic and water quality characteristics simulation of Poyang lake under the influence of changes in river basins and rivers in the past 10 years. - Journal of Environmental Science 35(5): 1274-1284.

[4] Duan, W., He, B., Nover, D., et al. (2016): Water quality assessment and pollution source identification of the Eastern Poyang Lake basin using multivariate statistical methods. Sustainability 8(2): 133.

[5] El-Serehy, H. A., Abdallah, H. S., Al-Misned, F. A., et al. (2018): Assessing water quality and classifying trophic status for scientifically based managing the water resources of the Lake Timsah, the lake with salinity stratification along the Suez Canal. Saudi Journal of Biological Sciences 25(7): 1247-1256.

[6] Gao, G., Ruan, Z., Qiulin, O. (2010): Water quality status and changing trend in Poyang Lake. - Journal of Nanchang Institute of Technology 29(4): 50-53.

[7] Hu, C., Zhou, W., Xiao, H., et al. (2010): Eutrophication state and normal distribution features of Poyang Lake. - Yangtze River 41(19): 64-68. 
[8] Lai, X., Shankman, D., Huber, C., et al. (2014): Sand mining and increasing Poyang Lake's discharge ability: a reassessment of causes for lake decline in China. - Journal of Hydrology 519: 1698-1706.

[9] Lan, Y. (2014): Forecasting performance of support vector machine for the Poyang Lake's water level. - Water Science 70(9): 1488.

[10] Liu, F., Li, M., Guo, Y. (2014): Quantitative analysis of time-space changes of water quality in Poyang lake and the impact of water level. - Journal of China Hydrology 34(4): 37-43.

[11] Liu, Q., Yu, C., Zhang, J., et al. (2013): Water quality variations in Poyang Lake. Journal of Agro-Environment Science 32(6): 1232-1237.

[12] Liu, X., Li, Y., Liu, B., et al. (2016): Cyanobacteria in the complex river-connected Poyang Lake: horizontal distribution and transport. - Hydrobiologia 768(1): 95-110.

[13] Ma, H., Xiao, Y., Liang, Y. (2013): Water quality assessment and treatment countermeasures analysis of Poyang Lake. - Journal of Anhui Agricultural Sciences 41(30): 12129-12131.

[14] Mao, Y., Zhou, X., Wang, M. (2014): Study on the eutrophication status in Poyang lake during lower water period. - Journal of Nanchang University (Natural Science) 38(6): 596-599.

[15] Napiórkowska-Krzebietke, A., Stawecki, K., Pyka, J. P., et al. (2013): Phytoplankton in relation to water quality of a mesotrophic lake. - Polish Journal of Environmental Studies 22(3): 793-800.

[16] Trolle, D., Spigel, B., Hamilton, D. P., et al. (2014): Application of a three-dimensional water quality model as a decision support tool for the management of land-use changes in the catchment of an oligotrophic lake. - Environmental Management 54(3): 479-493.

[17] Van Houtven, G., Mansfield, C., Phaneuf, D. J., et al. (2014): Combining expert elicitation and stated preference methods to value ecosystem services from improved lake water quality. - Ecological Economics 99: 40-52.

[18] Wang, S., Shu, J., Ni, Z., et al. (2013): Investigation on pollution situation and countermeasures in Poyang Lake. - Acta Scientiae Circumstantiae 3(04): 342-349.

[19] Wang, S., Ni, Z., Chu, Z., et al. (2015): Studies on the change of the river-lake relationship and its impact on water environment in Poyang Lake. - Acta Scientiae Circumstantiae 35(5): 1259-1264.

[20] Wu, L., Li, M., Guo, Y., et al. (2011): Influence of three gorges project on water quality of Poyang Lake. - Procedia Environmental Sciences 10: 1496-1501.

[21] Wu, Z., Lai, X., Zhang, L., et al. (2014): Phytoplankton chlorophyll a in Lake Poyang and its tributaries during dry, mid-dry and wet seasons: a 4-year study. - Knowledge Management of Aquatic Ecosystems 136(412): 06.

[22] Wu, Z., Zhang, D., Cai, Y., et al. (2017): Water quality assessment based on the water quality index method in Lake Poyang: the largest freshwater lake in China. - Scientific reports 7(1): 17999.

[23] Yao, J., Zhang, Q., Ye, X., et al. (2018): Quantifying the impact of bathymetric changes on the hydrological regimes in a large floodplain lake: Poyang Lake. - Journal of Hydrology (561): 711-723.

[24] Yuan, Y., Zeng, G., Liang, J., et al. (2015): Variation of water level in Dongting Lake over a 50-year period: Implications for the impacts of anthropogenic and climatic factors. - Journal of Hydrology 525(10): 450-456. 